\title{
The Prevalence of Birth Defects and Related Factors in Zanjan City (Northwest, Iran) During 2015-2016
}

\author{
Arezoo Safaei Nezhad ${ }^{1}$ (D), Maryam Mahmoudi* ${ }^{*}$ (D), Roghieh Kharaghani ${ }^{1 *(D)}$ \\ 1. Dept. of Midwifery and Nursing, Faculty of Midwifery and Nursing, Zanjan University of Medical Sciences, Zanjan, Iran \\ 2. Center of Clinical Competency, Zanjan University of Medical Sciences, Zanjan, Iran
}

\begin{tabular}{|c|c|}
\hline Article Info & ABSTRACT \\
\hline dol $10.30699 /$ jambs.26.118.48 & $\begin{array}{l}\text { Background \& Objective: Regional differences exist in the prevalence of birth } \\
\text { defects. This study was undertaken to determine the prevalence and related factors }\end{array}$ \\
\hline \multirow{3}{*}{$\begin{array}{l}\text { Received: 2018/01/9; } \\
\text { Accepted: 2018/07/15; } \\
\text { Published Online: } 01 \text { Sep 2018; }\end{array}$} & \\
\hline & Materials \& Methods: This descriptive analytic study was performed in Zanjan \\
\hline & province during 2015-2016. Data included 41265 child births, which were extracted \\
\hline \multirow[t]{2}{*}{$\begin{array}{l}\text { Use your device to scan and read the } \\
\text { article online }\end{array}$} & $\begin{array}{l}\text { province hospitals (country electronic childbirth register system). Data was analyzed } \\
\text { using descriptive, uni-variate, and multi-variate logistic regression tests. }\end{array}$ \\
\hline & $\begin{array}{l}\text { Results: The prevalence of birth defects in Zanjan was } 0.7 \% \text {. Gestational age (odds } \\
\text { ratio [OR]: } 0.917,95 \% \text { CI: } 0.869-0.967, P=0.002) \text { and birth weight }(\mathrm{OR}=0.999,95 \% \\
\text { CI: } 0.999-1.000, P<0.001) \text { reduced the chance of birth defects, while consanguineous } \\
\text { marriage of parents (OR: } 1.745, \mathrm{CI} 95 \%: 1.298-2.347, P<0.001) \text {, and mother's doctoral } \\
\text { degree increased its prevalence (OR: } 3.928,95 \% \text { CI: } 1.058-14.584, P=0.041) \text {. }\end{array}$ \\
\hline \multirow{2}{*}{$\begin{array}{l}\text { Corresponding Information: } \\
\text { Roghieh Kharaghani, } \\
\text { Dept. of Midwifery and Nursing, Faculty } \\
\text { of Midwifery and Nursing, Zanjan } \\
\text { University of Medical Sciences, Zanjan, } \\
\text { Iran Email: r.kharaghani@yahoo.com }\end{array}$} & $\begin{array}{l}\text { Conclusion: It seems that premarital counseling, screening tests before and during } \\
\text { pregnancy, and education, especially for being pregnant in appropriate age and } \\
\text { conditions, could be the suitable approaches for reducing birth defects. }\end{array}$ \\
\hline & Keywords: Congenital abnormalities, Prevalence, Risk factors, Iran \\
\hline (C) $\underset{\mathrm{BY}}{\mathrm{BHC}}$ & $\begin{array}{l}\text { cle distributed under the terms of the Creative Commons Attribution-noncommercial } 4.0 \text { International License } \\
\text { st in noncommercial usages with proper citation. }\end{array}$ \\
\hline
\end{tabular}

\section{Introduction}

Birth defects form by intrinsic, extrinsic or both pathologic processes and result in single or multiple structural, functional, or biochemical-molecular defects. Morphological abnormalities form by a structural, defect or abnormal formation of a tissue or an organ and functional abnormalities form by, cellular or enzymatic defects in the uterus. These abnormalities are diagnosed during prenatal period, during or after birth (during infancy) (1-3). Birth defects are of the major causes of children's mortality. According to the global burden of disease study of the World Health Organization (WHO), $17 \%$ to $42 \%$ of infants' mortality occur due to the birth defects. Also, $77 \%$ of children with birth defects are born alive, but have major disabilities that require extensive treatment and rehabilitation $(4,5)$ revealed birth defects are one of the causes of Years of Life Lost (YLL) in Iran. Most birth defects have unknown and multifactorial etiologies, as predisposing genetic characteristics, along with environmental factors (6). Thus, regional differences may play an important role in shaping patterns of birth defects and wide epidemiologic studies seem necessary to determine the prevalence and related factors with congenital abnormalities.
Significant differences are observed in the prevalence of birth defects in various populations of the world. The prevalence of birth defects in the Erbil is reported $3.06 \%$ (7), in China $1.9 \%$ (8), Lebanon $2.4 \%$ (9), Saudi Arabia 5.2\% (10), India 1.2\% (11), and Turkey $2.9 \%$ (12). In Iran, there are very limited studies on the prevalence of birth defects. A systematic review and meta-analysis reported the overall prevalence of birth defects in Iran was $2.3 \%$ (13). Identifying the effective factors in the occurrence of birth defects can help reduce mortality and morbidity rates, promote health indicators of children and infants, and achieve a healthier and more efficient community. Based on the researcher's reviews and systematic studies on the prevalence of birth defects in Iran $(13,14)$, only one study has been carried out in Zanjan; reported a high prevalence of nervous system defects in 2005 in Zanjan (15). The main objective of this study was to determine the prevalence and related factors in province (20152016) in order to identify the best strategies for prevention.

\section{Materials and Methods}

This descriptive-analytic study included 41265 live or dead births with a gestational age of $>22$ weeks in Zanjan province, recorded in Iranian Mother and Newborn 
(IMAN) system during 2015-2016. The IMAN is a webbased system for childbirth registration information in Iran. Registration of childbirth information is done by all Iranian hospitals in this system. All the birth data, related to 10 maternity hospital centers, including private, public, and social security hospitals in Zanjan city and its suburbs, including Abhar, Khorram-Darreh, Tarom, Mahneshan, Iijrod, Khodabandeh, and Soltanieh, as well as neonates born out of the hospital, like on the way, at home, and at rural birth centers were recorded. IMAN system is an important source for collection and evaluation of maternal and newborn health status in the country. For gathering data in the whole country, standard forms of the Iranian Ministry of Health and Medical Education Office are used. These forms completed by trained midwives and usually registered in the IMAN system by the one trained midwife. The IMAN data were matched with the provincial birth statistics, reported by the provincial civil registration office, for confirming the full coverage of data. These data included maternal characteristics, demographic data, infants' characteristics, and characteristics of stillbirth or dead neonates. This study was part of a protocol of the study which was approved by the Ethics Committee of Zanjan University of Medical Sciences by grant number of ZUMS.REC.1395.56.

Neonatal abnormalities are recorded in this system, based on the report of the midwife, obstetrician or gynecologist, when the newborn has visible abnormalities or positive signs in routine ultrasound report or genetics screening tests during pregnancy. To analyze the gathering data, they were described by mean, Standard Deviation (SD), frequency, and percentage. At first, the total newborns number with birth defects were extracted. Considering that some newborns had several birth defects, in order to check the kind, the birth defects, data was analyzed separately from the number of birth defects.

Then, for the analytic assessment, uni-variate and multi-variate logistic regression tests were used to determine the relationship between independent variables, using SPSS 16 (IBM Inc. Chicago, IL,
USA). Multivariate logistic regression was performed by backward stepwise selection method. Variables that entered the final regression models included maternal education, parity, number of abortions, chronic hypertension, preeclampsia, neonates' sex, gestational age, birth weight, and consanguineous marriage of parents. The signify-cance level was Pvalue $<0.05$.

\section{Results}

The most common birth defect was related to musculoskeletal abnormalities (43.6\%), followed by genitourinary and renal abnormalities $(15.7 \%)$, and undefined $(15.1 \%)$. Abnormalities of the eyes, ears, heart and vessels, Down syndrome, and chromosomal abnormalities had each a prevalence of $5.2 \%$ of the total abnormalities (Table 1). Of 41265 neonates born during 2015-2016 in Zanjan, 305 had abnormalities, resulting in the prevalence of birth defects at 0.6 to $0.7 \%$. The mean age of mothers was 27.7 years. Most mothers had a diploma education (32.4\%). In $11.4 \%$ of cases, parents had a consanguineous marriage (Table 2). Table 2 shows that based on uni-variate logistic regression, gestational age, birth weight, parental consanguineous marriage, preeclampsia or eclampsia, and maternal educational level had significant association with abnormalities $(P \mathrm{~s}<0.05)$ (Table 2). Based on multi-variate logistic regression analysis, after adjustment for variables of the number of pregnancies, abortions, chronic hypertension, preeclampsia or eclampsia, and neonate's sex, the Odds Ratio (OR) of abnormalities declined 0.917 per week of gestational age (95\% CI: 0.869-0.967, and $P$ $=0.002)$ and 0.999 per gram of birth weight $(95 \% \mathrm{CI}$ : $0.999-1.000, P<0.001)$. The consanguinity marriage between parents increased the risk of abnormalities 1.745-fold (95\% CI: $1.298-2.347$, and $P<0.001$ ). Abnormalities increased in women with doctoral educational level at 3.928 folds (95\% CI: $1.058-$ 14.584, and $P=0.041$ ) (Table 3).

\section{Table 1. Frequency of birth defects in Zanjan province during 2015-2016}

$\begin{array}{lcc}\text { Birth defect type } & \text { Number }(\mathbf{N}=\mathbf{3 0 5})^{{ }^{a}} & \text { Percent } \\ \text { Neural tube defects } & 20 & 6.5 \\ \text { Other anomalies of the nervous system } & 15 & 4.9 \\ \text { Genital, urinary and kidney } & 48 & 15.7 \\ \text { Cleft palate / cleft lip } & 21 & 6.8 \\ \text { Cardiovascular } & 16 & 5.2 \\ \text { Musculoskeletal } & 133 & 43.6 \\ \text { Digestive } & 21 & 6.8 \\ \text { Eyes and ears } & 16 & 5.2 \\ \text { Face and neck } & 32 & 10.4 \\ \text { Down syndrome and chromosomal abnormalities } & 16 & 5.2 \\ \text { Other not defined anomalies } & 46 & 15.1\end{array}$


Table 2. Test-retest reliability of the participation dimensions for each areas of occupations $(\mathrm{N}=55)$

\begin{tabular}{|c|c|c|c|c|c|}
\hline Variable & Number & Percent & $\begin{array}{l}\text { Odds } \\
\text { Ratio }\end{array}$ & CI $\% 95$ & P-value \\
\hline Mothers age* & 27.7 & 6.1 & 1.007 & $0.989,1.026$ & 0.456 \\
\hline Mothers education & 1274 & 3.1 & 1 & - & - \\
\hline Illiterate & 9149 & 22.2 & 0.804 & $0.454,1.422$ & 0.453 \\
\hline Elementary School & 9609 & 23.3 & 0.547 & $0.304,0.983$ & 0.044 \\
\hline Guidance and High School & 13380 & 32.4 & 0.630 & $0.358,1.108$ & 0.109 \\
\hline Diploma & 7521 & 3.1 & 0.627 & $0.346,1.134$ & 0.122 \\
\hline University & 80 & 0,2 & 3.506 & $0.987,12.461$ & 0.052 \\
\hline PHD & 1274 & 3.1 & 1 & - & - \\
\hline Others & 252 & 0.6 & 0.514 & $1.452,4.447$ & 0.514 \\
\hline Consanguineous Marriage (yes) & 4702 & 11.4 & 1.797 & $1.345,2.400$ & $<0.001$ \\
\hline Place of Residence (rural) & 16195 & 39.2 & 0.990 & $0.786,1.248$ & 0.934 \\
\hline \multicolumn{6}{|l|}{ Insurance } \\
\hline Urban Health Insurance & 1934 & 4,7 & 0.720 & $0.336,1.545$ & - \\
\hline Rural Health Insurance & 7058 & 17,1 & 0.631 & $0.334,1.192$ & 0.399 \\
\hline Social Security Insurance & 11202 & 27,1 & 0.621 & $0.337,1.146$ & 0.156 \\
\hline Others* & 2602 & 6,3 & 0.822 & $0.408,1.658$ & 0.128 \\
\hline $\begin{array}{l}\text { Imam Khomeini Insurance and without } \\
\text { Insurance }\end{array}$ & 1118 & 4.0 & 1 & - & 0.584 \\
\hline Gravidity* & 2.0 & 1.0 & 1.100 & $0.999,1.211$ & 0.053 \\
\hline Parity* & 0.8 & 0.9 & 1.089 & $0.968,1.226$ & 0.154 \\
\hline Abortion* & 0.2 & 0.5 & 1.169 & $0.965,1.415$ & 0.110 \\
\hline Gestational Age* & 38.4 & 2.0 & 0.817 & $0.798,0.836$ & $<0.001$ \\
\hline Birth Weight* & 3144.7 & 531.5 & 0.999 & $0.999,0.999$ & $<0.001$ \\
\hline Newborn Sex (boy) & 21165 & 51.3 & 1.152 & $0.917,1.447$ & 0.223 \\
\hline Mother's Underlying Illness & 479 & 1.1 & 2,015 & $0.947,4.286$ & 0.069 \\
\hline Chronic Hypertension & 1072 & 2.6 & 1.814 & $1.058,3.112$ & 0.031 \\
\hline Preeclampsia or Eclampsia & 1038 & 2.5 & 1.454 & $0.794,2.664$ & 0.225 \\
\hline Diabetes & 1373 & 3.3 & 1.191 & $0.667,2.127$ & 0.553 \\
\hline Thyroid Disease & 255 & 0.6 & 0 & 0 & 0.995 \\
\hline Heart Disease & 198 & 0.4 & 0 & 0 & 0.995 \\
\hline Anemia & 9 & 0.0 & 0 & 0 & 0.999 \\
\hline HIV or VDRL Positive Test & 1099 & 2.6 & 0 & 0 & 1 \\
\hline Others & 0 & 0 & 1.241 & $0.428,1.518$ & 0.504 \\
\hline Mother's Underlying Illness & 479 & 1.1 & 2,015 & $0.947,4.286$ & 0.069 \\
\hline
\end{tabular}

* mean \pm Standard deviation

a: Armed Forces, Oil, and Bank employer-based Insurances 
Table 3. Factors related to birth defects based on multi-variate regression

\begin{tabular}{|lccc|}
\hline \multicolumn{1}{c}{ Variable } & Odds Ratio & \%95 CI & P-value \\
\hline Gestational age & 0.917 & $0.869,0.967$ & 0.002 \\
Birth weight & 0.999 & $0.999,1.000$ & $<0.001$ \\
Consanguineous marriage (yes) & 1.745 & $1.298,2.347$ & $<0.001$ \\
Mothers education & 1 & - & - \\
\hline Illiterate & 0.918 & $0.515,1.636$ & 0.772 \\
Elementary school & 0.642 & $0.354,1.162$ & 0.143 \\
Guidance and high school & 0.741 & $0.417,1.315$ & 0.305 \\
Diploma & 0.757 & $0.414,1.383$ & 0.366 \\
University & 3.928 & $1.058,14.584$ & 0.041 \\
PHD & 1.963 & $0.630,6.116$ & 0.245 \\
\hline Others & & & \\
\hline
\end{tabular}

* Adjusted for maternal age, mother's education, type of insurance, place of residence, gravida, abortion, mother's underlying illness, forceps or vacuum delivery, and sex

\section{Discussion}

The prevalence of birth defects in Zanjan- Iran was $0.7 \%$ with the highest prevalence for musculoskeletal and genito-urinary abnormalities. There was a significant association between birth defect and gestational age, birth weight, consanguineous marriage of parents, and maternal educational level (All $P_{\mathrm{s}}<0.05$ ).

Although, the prevalence of abnormalities is different in the world, its prevalence in developing countries is similar to developed countries. The prevalence of abnormalities in Iran is reported at about $2.3 \%$ with $95 \%$ CI of 1.8 to $2.9 \%$. The prevalence of abnormalities in this study was less than the rate of the entire country, but close to the prevalence of $1.12 \%$ reported in Tabriz (16), $0.82 \%$ in Ardabil (17), and $0.01 \%$ in Urmia (18). The difference in the prevalence of birth defects can be due to the difference in genetic, cultural, racial factors, socio-economic status, diagnostic methods, and failure to register. The prevalence of birth defects may be underestimated in this study.

The highest prevalence of birth defects in the present study were musculoskeletal, followed by genito-urinary abnormalities. These results are consistent with other studies conducted in other cities in Iran $(13,17,19,20)$. It may be because of the fact that these abnormalities are visible after birth. Accurate diagnosis of congenital abnormalities, depending on the type of abnormality, may besides physical examination require ultrasound before birth, echocardiography, etc. But, the results of the present study are only based on documents registered in IMAN system, registering cases based on the examination of the birth team and pediatricians. Ajibola et al. (2017) showed in a longitudinal study that $40 \%$ of birth defects were not recognizable at birth and were discovered in subsequent Follow-ups (21). It is suggested that the prevalence of birth defects in infancy and child- hood be assessed with appropriate diagnostic methods and reported in an appropriate surveillance system.

Gestational age and birth weight had significant relationship with birth defects that are consistent with other studies in this area $(9,19,22)$. It seems that fetuses with birth defects grow less and are born sooner than other babies. Similar to previous studies $(9,17)$. Considering that growth and developmental disorders are more common in birth defects, there is a significant relationship between the prevalence of birth defects with low birth weight and gestational age. Parents with consanguineous marriage were about twice more likely than other parents to have a child with birth defect. In Iran, 37.4\% of marriages are consanguineous (22). Consanguineous marriage plays a vital role in expression of hidden genes, which can cause genetic abnormalities. Saki-Malehi et al. (2017) showed in Iran those women who had consanguineous marriages were 4.4 times more likely to give birth to infants with microcephaly (23). Therefore, the role of premarital counseling, especially in people with a consanguineous marriage, should be considered more than ever. For preventing birth of neonates with abnormality, factors like premarital counseling, preconception counseling, and screening during pregnancy, especially in consanguineous marriages should be considered and their efficiency in the prevention of abnormalities should be evaluated.

The birth defects correlated with doctoral degree of maternal education in women. In multi-variate regression, abnormalities were significantly correlated with maternal education, so that increased years of education, compared to illiterates, decreased the abnormalities sharply, while abnormalities increased in women with doctoral degree. The association between education and abnormalities has been shown previously (24). It is expected that increased awareness of people with higher education decrease the abnormalities, despite this, abnormalities increased in 
women who had a doctorate degree that is alarming for the society and may reflect the effects of age. It seems that delayed conception because of education or any other reason can increase the risk of abnormalities, so serious warning should be given to couples in terms of appropriate age and conditions for conception. Public education about appropriate age for fertility can be effective.

\section{Conclusion}

The prevalence of birth defects in this study was lower than the country rates. Health planning and policymaking to control the risk factors and identifying highrisk people, like parent with consanguineous marriage, could lead to further decline in congenital abnormalities. Also, premarital counseling for appropriate ages and conditions of conception, preconception counseling, and screening during pregnancy may reduce congenital abnormalities. In a general assessment, the findings of this study are considerable because of registration of all births in the province during two consecutive years. But this study was conducted based on the data recorded in IMAN system, according to the reports of the midwife, obstetrician or pediatrician, which could be a limitation of this study.

\section{Acknowledgment:}

Researchers appreciate the great efforts and cooperation of Iranian Ministry of Health and Medical Education Office, and the honorable research deputy of Zanjan University of Medical Sciences. Also, all centers inside and outside hospitals in Zanjan province that had a significant role in data collection are appreciated. This study was part of protocol of the study "Prevalence and Related Factors in still birth in Zanjan Province". This protocol was approved by the Ethics Committee of Zanjan University of Medical Sciences by grant number of ZUMS.REC.1395.56.

\section{Conflict of Interest:}

The authors declared no conflict of interest regarding to this paper.

\section{References}

1. DeSilva M, Munoz FM, Mcmillan M, et al. Congenital anomalies: Case definition and guidelines for data collection, analysis, and presentation of immunization safety data. Vaccine. 2016; 34(49): 6015-26. [DOI:10.1016/j.vaccine.2016.03.047] [PMID] [PMCID]

2. World Health Organization. Congenital anomalies, Fact sheet: World Health Organization; Available from: http://www.who.int/mediacentre/factsheets/fs370/en

3. Stevenson RE, Everman DB. Human malformations and related anomalies: Oxford University Press; 2015. [DOI:10.1093/med/9780199386031.001.0001]

4. Boyle B, Addor M-C, Arriola L, et al. Estimating global burden of disease due to congenital anomaly: an analysis of European data. Arch Dis Child Fetal
Neonatal Ed: 2018; 103(1): F22-F28. [DOI:10.1136/archdischild-2016-311845] [PMID] [PMCID]

5. Moradi-Lakeh M, Sepanlu SG, Karimi SM, et al. Trend of socio-demographic index and mortality estimates in iran and its neighbors, 1990-2015; Findings of the global burden of diseases 2015 study. Arch Iran Med. 2017; 20(7): 419-28.

6. Ergaz-Shaltiel Z, Fudim-Weinstein L, Patlas N, DrorShoshani D, Neeman-Azulay M, Ornoy A. Free communications. Reprod Toxicol. 2014; 48: 12-14. [DOI:10.1016/j.reprotox.2014.07.002]

7. Go Othman. The prevalence and types of congenital anomalies in newborns in erbil. Med J Islamic World Acad Sci. 2013; 1: 31-34. [DOI:10.12816/0000209]

8. Xie D, Yang T, Liu Z, Wang H. Epidemiology of birth defects based on a birth defect surveillance system from 2005 to 2014 in Hunan province, China. PloS One. 2016; 11(1): e0147280. [DOI:10.1371/journal. pone.0147280] [PMID] [PMCID]

9. Francine R, Pascale S, Aline1a H. Congenital anomalies: prevalence and risk factors. Univers $\mathrm{J}$ Pub Health. 2014; 2:58-63.

10. Sallout B, Obedat N, Shakeel F, Mansoor A, Walker M, Al-Badra A. Prevalence of major congenital anomalies at king fahad medical city in saudi arabia: a tertiary care centre-based study. Ann Saudi Med. 2015; 35(5): 343 51. [DOI:10.5144/0256-4947.2015.343] [PMID] [PMCID]

11. Cherian AG, Jamkhandi D, George K, Bose A, Prasad J, Minz S. Prevalence of congenital anomalies in a secondary care hospital in South India: A crosssectional study. J Trop Pediatr. 2016; 62(5): 361-67. [DOI:10.1093/tropej/fmw019] [PMID]

12. Tomatir A, Demirhan H, Sorkun H, Köksal A, Özerdem F, Cilengir N. Major congenital anomalies: a five-year retrospective regional study in Turkey. Genet Mol Res. 2009; 8(1): 19-27. [DOI:10.4238/vol8-1gmr506]

13. Vatankhah S, Jalilvand M, Sarkhosh S, Azarmi M, Mohseni M. Prevalence of congenital anomalies in Iran: A review article. Iran J Public Health. 2017; 46(6): $733-$ 43.

14. Pasha YZ, Vahedi A, Zamani M, Alizadeh-Navaei R, Pasha EZ. Prevalence of birth defects in Iran: a systematic review and meta-analysis. Arch Iran Med. 2017; 20(6): 376-85.

15. Marzban A, Sadeghzadeh M, Nasab N. Incidence of gross congenital anomalies in newborns in Zanjan. J Mazandaran Uni Med Sci. 2005; 9: 33-8.

16. 16 Mashhadi Abdolahi H, Kargar Maher MH, Afsharnia F, Dastgiri S. Prevalence of congenital anomalies: a community based study in the Northwest of Iran. ISRN 
Pediatrics. 2014: 2014: 1-5. [DOI:10.1155/2014/ 920940] [PMID] [PMCID]

17. Alijahan R, Mirzarahimi M, Ahmadihadi P, Hazrati S. Prevalence of congenital abnormalities and its related risk factors in Ardabil, Iran, 2011. Iran J obstet gynecol. 2013; 16: 16-25.

18. Abdi-Rad I, Khoshkalam M, Farrokh-Islamlou H-R. The prevalence at birth of overt congenital anomalies in Urmia, Northwestern Iran. Arch Iran Med. 2008; 11(2): 148-51.

19. Jalali SZ, Fakhraie SH, Afjaei SA, Kazemian M. The incidence of obvious congenital abnormalities among the neonates born in Rasht hospitals in 2011. J Kermanshah Univ Med Sci. 2015; 19: 109-17.

20. Rostamizadeh L, Bahavarnia SR, Gholami R. Alteration in incidence and pattern of congenital anomalies among newborns during one decade in Azarshahr, Northwest of Iran. Int J Epidemiol Res. 2017; 4: 37-43.
21. Ajibola G, Zash R, Shapiro RL, et al. Detecting congenital malformations-lessons learned from the Mpepu study, Botswana. PloS One. 2017; 12(3): e0173800. [DOI:10.1371/journal.pone.0173800] [PMID] [PMCID]

22. Hosseini-Chavoshi M, Abbasi-Shavazi MJ, Bittles AH. Consanguineous marriage, reproductive behaviour and postnatal mortality in contemporary Iran. Hum hered. 2014; 77(1-4): 16-25. [DOI:10.1159/000358403] [PMID]

23. Saki-Malehi A, Seddigh Rad G, Sayyahi A, MousaviFar F, Veysi M, Rahim F. The pattern of inherited microcephaly and role of the consanguineous marriage: A study from Southwestern Iran. Ethiop J Health Develop. 2017; 31(2): 119-123.

24. Sachdeva S, Nanda S, Bhalla K, Sachdeva R. Gross congenital malformation at birth in a government hospital. Indian J Public Health. 2014; 58(1): 54-6. [DOI:10.4103/0019-557X.128170] [PMID]

\section{How to Cite This Article:}

Safaei nezhad A, mahmoodi M, kharaghani R. The Prevalence of Birth Defects and related Factors in Zanjan City (Northwest, Iran) during 2015-2016. J Adv Med Biomed Res. 2018; 26 (118) :48-53

\section{Download citation:}

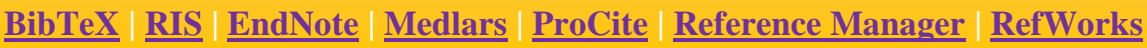

\section{Send citation to:}

8 Mendeley 2 Zotero ;) RefWorks RefWorks 